\title{
23
}

\section{MAPPING URBAN SPACES WITH THE USE OF PHYSICAL, DIGITAL, AND AUGMENTED REALITY MODELS}

\section{Experiences from Applications in Architectural and Urban Education}

\section{Tomasz Bradecki}

\section{Introduction}

At the meeting point of architecture, urban planning, geography, and cartography, a specialization can be identified that focuses on mapping spatial information and related data. According to the Cambridge Dictionary definition, mapping is the activity or process of making a map, or an image or diagram, that represents something (Cambridge Dictionary). "Mapping urbanism data" is becoming more and more popular due to the increasing possibilities of acquiring, collecting, and processing more and more data. The availability of services (e.g., Google Earth, OpenStreetMap) and local spatial information systems (national, regional, municipal, cadastral) is also increasing. However, data are usually structured with different criteria, which makes comparative analysis of multiple cities challenging (Valls et al., 2014). The possibilities of data processing and presentation are becoming more and more accessible owing to many tools available on the Internet (e.g., cadmapper.com, mapacad.com, schwarzplan.eu, osm2world.org, puma.worldbank.org/tool/). GIS is no longer trapped on the desktop and can be shared via the Internet and standard web browsers allowing consumers to utilize this visual information source without having to purchase and download any specialized software (ESRI, 2014). There are many impressive examples of data mapping, for example, www.viewsoftheworld.net, www.vividmaps.com. One example of processed data illustrates the spatial development of 66 global cities around the world and the change in population density in the years 1988-2014. Owing to the comparison of mapped data, it is easy to conclude that the vast majority of cities recorded a decrease in population density with a simultaneous significant increase in the surface of urbanized areas. The maps show the scale of the changes very clearly; it is easy to see analogies in the development of different cities. Mapping is also used to study future scenarios. Based on data analysis, Gao and O'Neill produced an empirically grounded set of global, spatial mappings of possible directions of urbanization expansion in urban areas in the 21st century (Gao, J., O'Neill, B.C., 2020).

Various data are mapped, for example, demographic data (e.g., crime rates, population density, level of crime), data related to the built environment (e.g., intensity of building 
development, building height, urban areas), as well as economic data (e.g., real estate prices, income level). Mapping uses a "cellular automata model," which can be a script that spatially matches data to cells of a certain size. This type of script can be used for mapping in the scale of cities (e.g., Sandeep Maithani 2010) or entire countries (Yanlei Feng, Yi Qi 2018). Some of the research results, in which data are mapped, are presented in the form of $3 \mathrm{D}$ models, due to the clarity of the message, and the ease of drawing conclusions.

Mapping is frequently used to create land-use structure maps. In this regard, the shared data, plans, and orthophotos enable fully programmed mapping. However, there are some limitations, such as confusing land plots of mixed functional types, complex and heterogeneous urban landscapes that pose a challenge for land-use maps (Tengyun Hu, Jun Yang, Xuecao L, Peng Gong 2016). Also challenging are atypical mappings presenting data in the form of $3 \mathrm{D}$ models, or presenting changes in the values of the analyzed data over time, for example, to present changes in Manhattan's intensity of building development as presented by McQuilkin (2014).

\section{Mapping for Education in the Project-Based Learning Formula}

Mapping data in the form of spatial models can be useful in education in the field of architecture and urban planning for the purpose of demonstrating some of the characteristics of urbanized spaces. Mapping can be used for comparative analysis of public spaces, to express the theory, to designate places or areas, or to illustrate the values of urban indicators, for example, intensity of building development. All of the mentioned ones can be effective in the form of 3D mappings due to their connection with the physical structure of the city. The visual representation of data and city elements allow the exploration of complex datasets and can improve the collaboration of the teams involved through better communication (Zlatanova, Itard, Kibria, \& Van Dorst, 2010). The use of touch-screens, smartphones, and medium-sized tablets equipped with high-speed wireless connections, GPS, and longlasting batteries have allowed to develop new pedagogical strategies, despite the size limitations of the screens (Fonseca et all. 2017).

The Project-Based Learning (PBL) formula is often used in the education process. The popular notion of PBL advocates for students working in teams, undertaking complex design challenges, in an environment similar to real professional life (Stangel M. Twardoch T. 2016). Urban design education allows students to understand urban issues in cities and urban environments as an integral part of people's lives and to create designs and solutions on an urban scale (Mahgoub Y. 2015). Alcock and Blyt emphasize that the method creates a kind of PBL environment in which experiences from different cases are rarely repeatable; they also mention the advantages of differentiating approaches in different cases (G.L. Alcock, H. Blyt 2010). Another example of data use is Francesc Valls, who proposed with his team an approach to data mining from social networking sites that was used to outline strategic requirements for an urban design in the PBL architecture course (Valls F. et al. 2020). They proved that it is possible to present a visualization of the results, in a way designed to be attractive and informative for both students and professionals - even without a technical background - so the analysis conducted may be reproducible in other urban data contexts (Valls F. et al. 2020).

In the case of the city structure analysis, the PBL method most often means a multiaspect analysis and diagnosis of city problems. The author has conducted a series of research in this 
area in the PBL formula. As part of the experiments, during the project exercises, analyses of the cities of the Upper Silesian Metropolitan Group (2018), the city of Bologna (2019), and the city of Aachen (2020) were carried out. The research was carried out at the Faculty of Architecture of the Silesian University of Technology in several third-year project groups majoring in architecture and urban planning. Due to the complexity of the problem, all experiments were carried out in multiperson groups to obtain effects in the form of digital and physical models. The implementation of models presenting the values of selected urban indicators or other data, as well as public spaces, constitutes an unusual and unique attempt at this stage of education and seems to be effective. The conclusions from the research during the implementation of subsequent cases are described below.

\section{GZM Mapping Case - Physical Models Based on the Developed Data}

One of the reasons why work on the project was started was the establishment of Metropolis GZM (Górnośląsko-Zagłębiowska Metropolia). The metropolis was established on March 9, 2017, and it was a completely new legal form integrating such a large $\left(2,500 \mathrm{~km}^{2}\right)$ and diverse area (population 2.3 million; Metropolis GZM). The metropolis is made up of 41 cities and communes in the area of Upper Silesia and Dąbrowa Basin, and it is the area with the highest population density in Poland and Europe $\left(881\right.$ people $/ \mathrm{km}^{2}$ ). The main aim of the activities and the starting point for the analyses was a detailed study of the structure of communes making up the entire metropolis and illustrating the connections, similarities, and differences between them.

The result of the project was a model representation of the structure of the Metropolitan Association of Upper Silesia and Dąbrowa Basin. It included diagrams of the structure of green areas and agricultural areas, land use, infrastructure, communication, demographic structure, public spaces, and the structure of housing development (Bradecki T. Cabaj M. 2018). Models of the demographic structure and density of buildings were presented using two models.

An example of the analysis of the diversity of the demographic structure shows that the use of a fully automated cellular model is not possible. The demographic structure of the GZM is complex: some areas are characterized by high population density (on average 13 people/ha - urban areas), while others are low (on average 2 people/ha - rural areas), but the average result is 9 people/ha. A model was prepared to demonstrate the diversity of the population structure in the GZM: the GZM area was divided into $3 \mathrm{~km} \times 3 \mathrm{~km}$ quadrats which gives a size of $3 \times 3 \mathrm{~cm}$ in the scale model. For individual communes, the total population was analyzed, including the division into districts and data on districts, villages, or other administrative areas included in the statistics of communes. The collected data were averaged for the needs of the synthetic model: the number of people in the districts per area of the model was analyzed and averaged. Similar calculations were performed for the needs of building-density analyses (percentage share of buildings). The data prepared in this way were presented in the form of a physical model (Figure 23.1). This model was recalculated and implemented as a mock-up during the classes, owing to which the students had to take into account the scale and present the differences between individual areas.

For the purposes of comparing the structure of selected public spaces, 49 cases were analyzed. Each of the cases was designated as an area of $250 \times 250 \mathrm{~m}$. Selected fragments of the building structure were obtained as 2D drawings (Figure 23.2) using the cadmapper. 

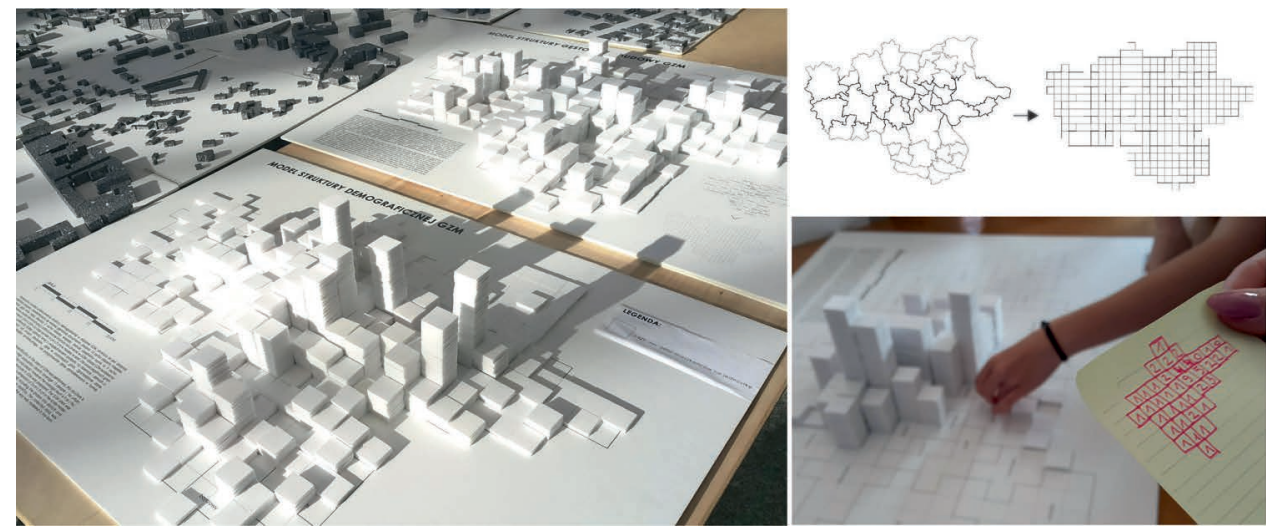

FIGURE 23.1 Physical models showing the diversity of building density and population density in the GZM, a diagram of the administrative division and the corresponding cellular model, the process of creating the mock-up (2018).

com platform, and then digital models were prepared (Figure 23.2) based on the data in openstreetmaps and the resources of the local bank database of the Central Statistical Office (GUS), as well as on the basis of own research and observations in the field. Physical models of individual spaces were made on a scale of 1.500. The models were made of polystyrene on a cutting plotter, which allowed for the preservation of the uniform character of 49 mockups performed by a group of 44 students. The entire mock-up was $5 \times 2.5 \mathrm{~m}$ (Figure 23.2). Owing to such a large scale, the public spaces presented could be visually identified from a considerable distance of several meters, and the visual comparison of mock-ups standing next to each other was very easy.

\section{Bologna Mapping Case - Physical and 3D Models Based on Data}

The selection of Bologna as the city to be analyzed and mapped resulted from the need to prepare a larger group of students to participate in the international research and education project, ArchéA. The result of the research in a group of 16 students were models and plans based on the data obtained from the local spatial information system and made available by the Bologna city authorities (as part of the cooperation between the University of Bologna and the city authorities).

In the city scale, statistical areas for which data can be obtained turned out to be of major importance. In the case of Bologna, there are as many as 90. In a team of 16 people, a model of intensity of building development was created. The model is presented in a synthetic approach (the area of Bologna was divided into squares; simplifications were adopted on the border of statistical areas in the areas of squares). A similar model was implemented for the share of built-up areas indicator. In this case, each statistical area was distinguished as the shape of its boundaries. A scale of $20-80 \%$ of the built-up area was adopted. On this basis, a model was created illustrating the shapes of individual city areas and at the same time the share of buildings expressed by height: the higher the share of buildings, the greater the height of the mockup element (Figure 23.3). The experiment also included a mock-up illustrating the elements of Kevin Lynch's theory for the city of Bologna (Figure 23.3). With the help of sticks, threads, 

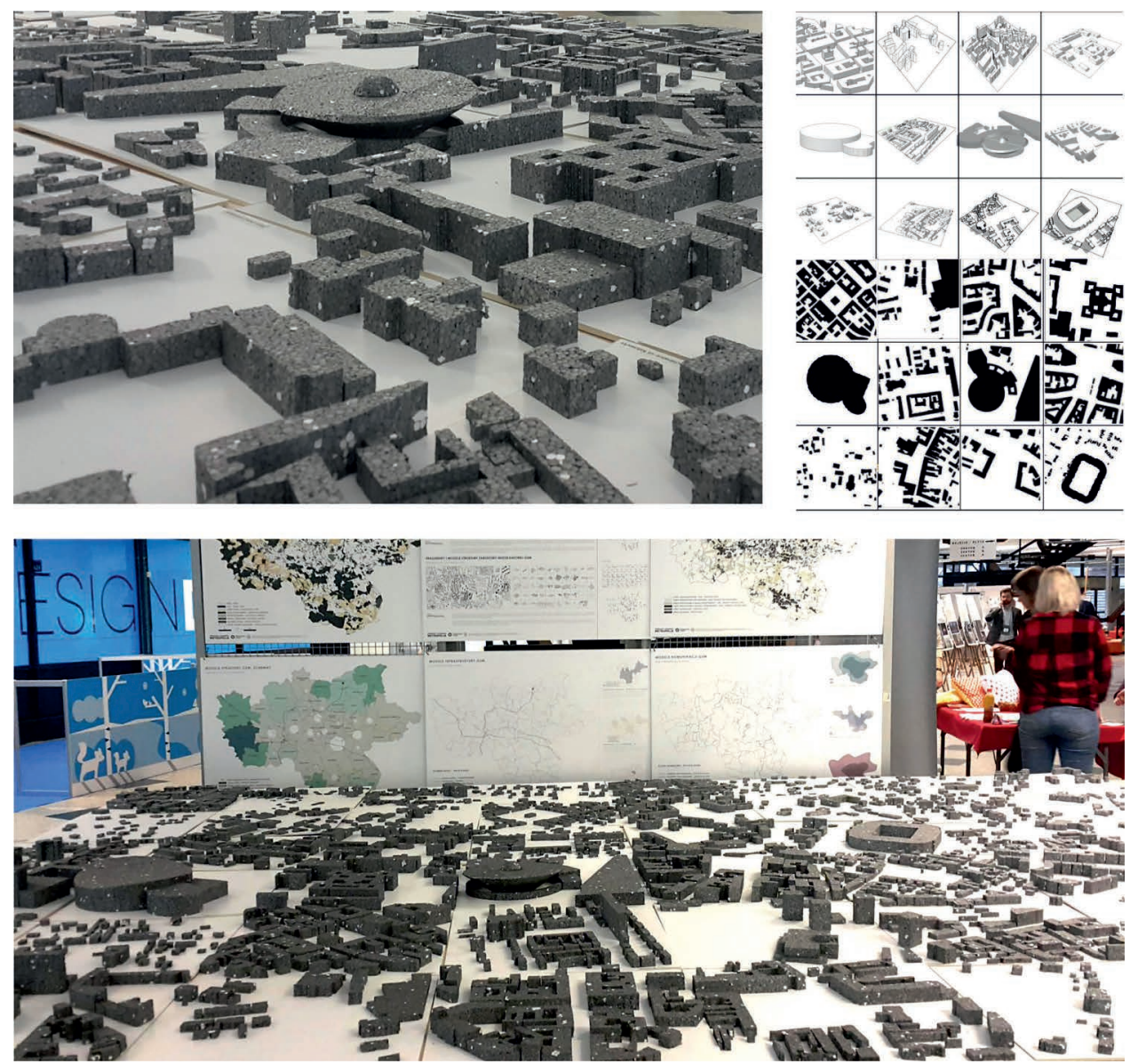

FIGURE 23.2 Mapping selected public spaces in the GZM area, plans, 3D models (2018), a $2.5 \times 5$ m mock-up during the exhibition presenting the GZM during the 4 Design Days, Spodek, Katowice (2019).

colors, and photo thumbnails, the following were presented: roads, junctions, edges, areas, and landmarks (Lynch K. 1960).

\section{Aachen Mapping Case - Augmented Reality Models}

Augmented reality (AR) is the extension of digital models and virtual reality, which is becoming more and more popular. Augmented reality refers to the combination of virtual objects and real-world environment, so that users can experience a realistic illusion when using the interactive virtual object to explore the real-world environment (Kan T. 2011). Most commonly used for this purpose are tablets or smartphones with a specialized application. The use of AR in urban planning is becoming more and more available. The visualization of the erecting of buildings in a given site in the area using a smartphone, based on a local plan, is already used in practice. The depiction of three-dimensional (3D) data is crucial for urban planning stages. Importance of new technologies usage is indisputable (Cirulis A., Brigmanis K. 2013). 


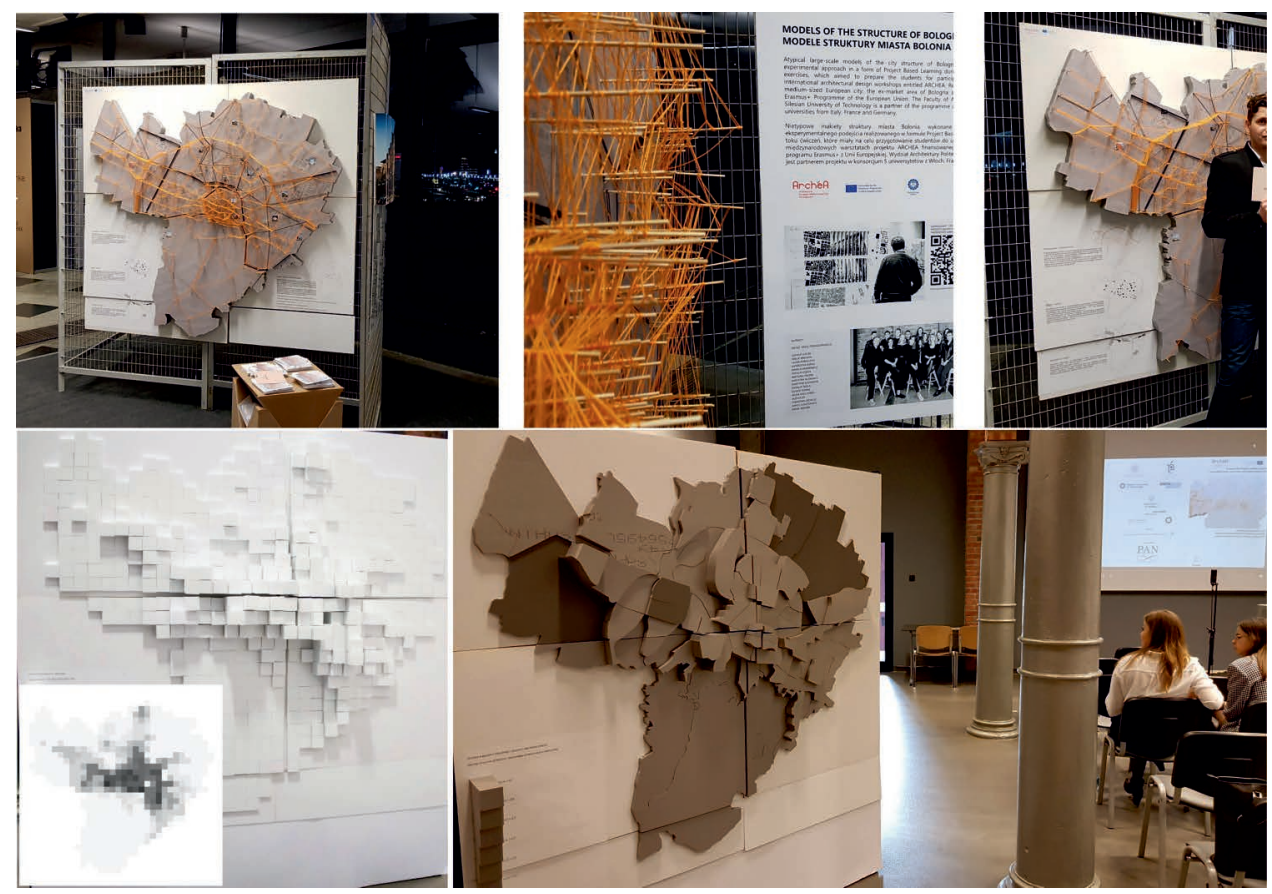

FIGURE 23.3 Models presenting the mapping of the city of Bologna: mapping city image elements according to Kevin Lynch's theory, mapping the percentage share of buildings, intensity of building development, 2019.

The aim of the exercise was to present models of the structure of the city of Aachen with the use of a smartphone application. After many attempts, it was possible to create 3D models of intensity of building development, population density, and accessibility of public space and other landmarks and structures, which were implemented in the form of physical and 3D mock-ups. The aim of the exercise was to provide viewers with an additional opportunity to experience the physical model through a 3D walk with their own smartphone. The exercise made use of 3D modeling software ArchiCAD and SketchUp, data and 3D models made available online, and the AR application available for installation on a smartphone (Figure 23.4). Displaying the models on one's own smartphone is dynamic, that is, the rotation of the models occurs simultaneously with the rotation of the smartphone in one's hands. The fact that this kind of experiment is possible in an academic setting proves that AR can be used in a simple and effective way. The analysis of public spaces in terms of pedestrian accessibility and the theory according to Kevin Lynch was also carried out in the form of 3D models, where selected elements were presented as an abstract model (in the form of semitransparent solids) superimposed on a fragment of the Aachen city model. The model prepared in this way was especially popular when viewed on a large-scale touchscreen (Figure 23.5).

\section{Conclusions}

All the described cases were carried out in the same way: the didactic process lasted about 4 months in a multiperson group, and the results were published online as well as during 


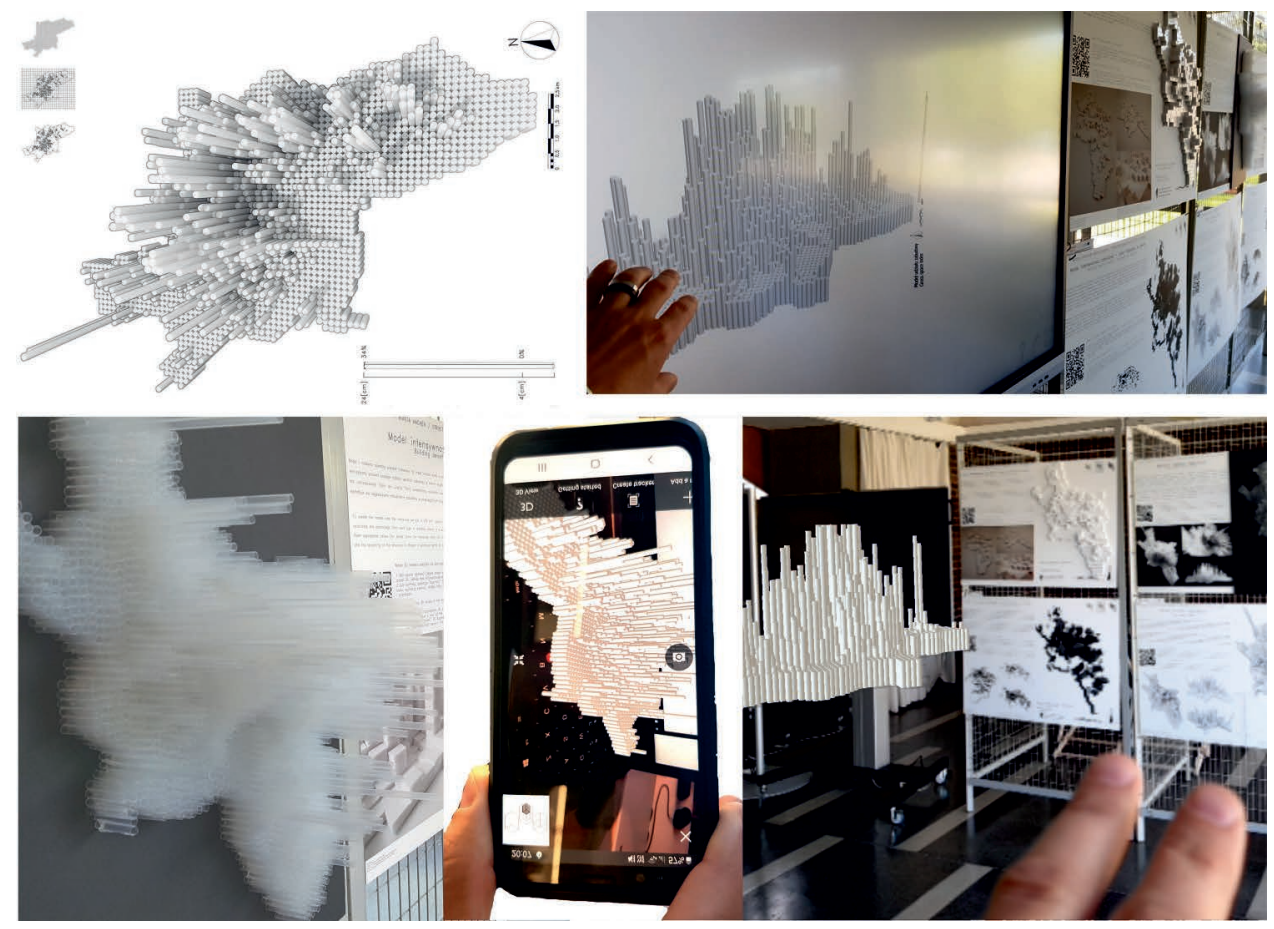

FIGURE 23.4 Physical model, 3D model - mapping visualization for the city of Aachen 3D model with the possibility of interactive viewing through a large-scale touchscreen monitor and virtual reality frames from a smartphone - mapping visualization for the city of Aachen - materials from the summary exhibition, 06.2020.

public exhibitions and presentations. Models presenting GZM and Bologna were displayed during the annual 4 Design Days fair in Katowice as part of the 2019 and 2020 editions [4dd.pl]. Several thousand visitors watched the models at each of those events. The presented experiments allowed to draw the following conclusions. Mapping public spaces turned out to be much more effective in the 2D variant and the physical model. Despite the fact that the $3 \mathrm{D}$ models were created in the same way with the same level of detail, their analysis in the form of individual model views was not effective and useful. On the other hand, the physical models made and presented side by side were much more useful. The viewers of the mock-ups identified the selected places and moved around the mock-up to make comparisons easier.

Mapping public spaces in the form of 3D models with the use of AR should also be assessed positively. The interaction of the viewer and the ability to change views between the physical structure of the city and the mapping performed were the method's advantage. It seems that the ability to easily identify a selected place in the city and a given issue that is the subject of analysis produces the best results in presenting the problem and understanding it by the viewer. The disadvantage of AR is the need to use additional devices or applications. The observations from the exhibition of models of Aachen city showed that the participants of the exhibition were much more eager to view the models in a traditional way than with the use of AR. This was shown by website traffic statistics. 

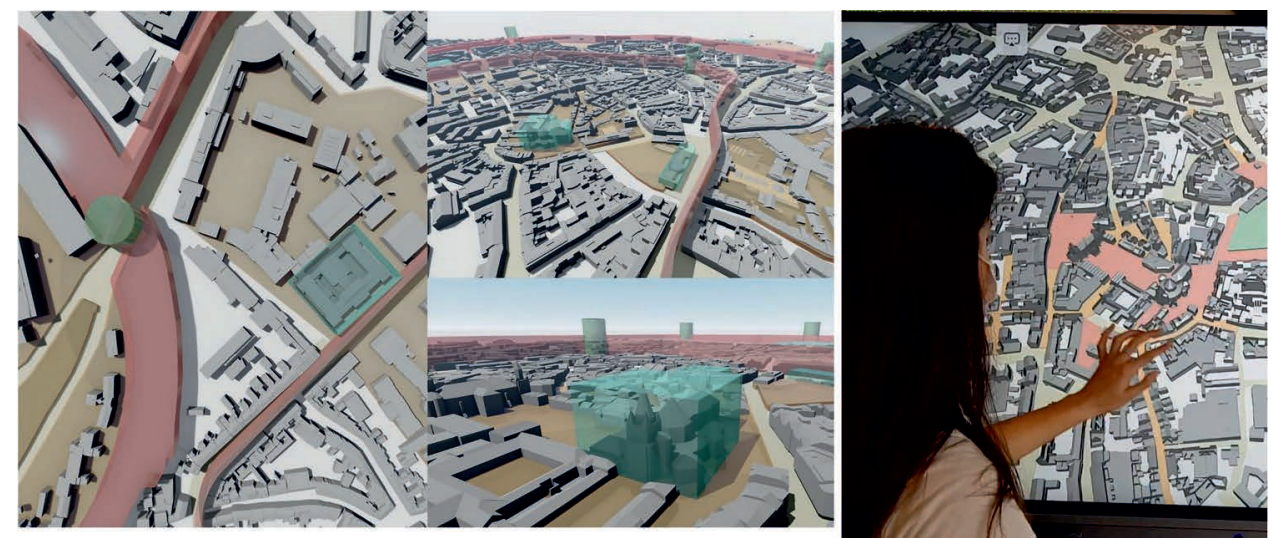

FIGURE 23.5 3D mapping of a fragment of the city of Aachen; analysis of elements identifying the city according to the theory of Kevin Lynch; an interactive model of mapping the accessibility of public spaces for pedestrians available on a large-format touch display hybrid exhibition 2020.

The above examples are the result of activities carried out as part of didactics, and, therefore, they are burdened with errors. Nevertheless, these are activities that correspond to similar professional studies and, at the same time, enable to understand the relationship between the visualized data and the physical structure of the city. The line between the 3D digital model and the real model is blurred. The increasing availability of various tools allows for the easy implementation of the real model based on the 3D model. It is also possible to extend a very simple physical model through AR. Working in real time on $3 \mathrm{D}$ models and AR turned out to be particularly effective during remote learning, due to the necessity to process the model together (a team of students and the teacher).

Data mapping should be assessed as useful in urban analysis. Data mapping in the form of 3D models should also be considered useful, to a large extent, in didactics and preparation of presentation materials for recipients who do not need to have specialist knowledge. The sophistication of maps and models that are created from the data depends on their detail and segregation. Developing mapping methodology with the use of 3D models and analyzing broadly understood data (big data) with the use of professional solutions (including confidential data analysis) may be useful for a better understanding of modern cities. The methodology can be useful in the analysis of the latest technologies that favor the development of a 'smart city'.

\section{Acknowledgments}

The case of GZM mapping was carried out under a scientific and research agreement concluded between the Board of Metropolis GZM and the Faculty of Architecture of the University of Technology (WAPŚ) and performed in spring 2018. The experience gained in the mapping cases of Aachen and Bologna was used in the international project, ArchéA urban open space in European medium-sized cities financed by the European Commission Erasmus KA2 Action project ref. 2018-1-IT02-KA203-048305 website: https: //site.unibo. it/ArchéA/en [access 2020.01.04] 
Mapping GZM case study

Website: http://urbanmodel.org/en/models-of-the-structure-of-the-upper-silesianzaglebie-metropolis/ [access 2020.01.04]

Video: https://youtu.be/I31QU2_bPoc

Academic tutor: Tomasz Bradecki; authors: Małgorzata Olszańska, Anna Krawczyk, Agnieszka Sztabkowska, Agnieszka Janas, Magdalena Opania, Mateusz Śnieżek, Agnieszka Liszka, Helena Turczyn, Alicja Kochańska, Aleksandra Kuśmierz, Marcin Woźnica, Patrycja Dapa, Marta Cabaj, Magdalena Opania, Wiktoria Dziaduła, Mateusz Śnieżek, Sylwia Bluszcz, Klaudia Bugla, Olga Dramska, Roksana Drosd, Marek Grąbczewski, Karolina Grzesista, Krzysztof Łyszkowski, Jakub Kapral, Małgorzata Karolak, Kamila Korona, Dawid Krzeszowiec, Oliwia Kwaśniewska, Maciej Moszant, Marcin Noras, Agnieszka Paul, Jakub Pielecha, Natalia Płoskonka, Karolina Rusek, Michał Słota, Klaudia Sosna, Piotr Szenkowski, Zuzia Szmatłoch, Damian Śliwiński, Artur Tomczyk, Joanna Weźranowska, Magdalena Wojtowicz, Angelika Woźniak, Monika Wrodarczyk, Julia Zubek

Mapping Bologna case study website: http://urbanmodel.org/en/models-of-the-structureof-the-city-of-bolonia/ [access 2020.01.04] VIDEO: https://youtu.be/tIDoR3Ae5_Y

Academic tutor: Tomasz Bradecki; authors: Joanna Golba, Emilia Jaromin, Laura Konieczny, Katarzyna Korus, Anna Kurianowicz, Natalia Kyzioł, Wiktoria Paszek, Karolina Słomiany, Martyna Suchanek, Natalia Tadla, Oliwia Tomas, Anna Wieczorek, Alex Duży, Sebastian Dziwisz, Karol Subotowicz, Kamil Wróbel

Mapping Aachen case study website: http://urbanmodel.org/en/models-of-the-structureof-the-city-of-aachen-2/ [access 2020.01.04] Video: https://youtu.be/wH4pH0GV3e4

Academic tutor: Tomasz Bradecki; authors: Karolina Piotrowska, Ościłowicz Olga, Górnikiewicz Grzegorz, Sikorska Patrycja, Baryłowicz Katarzyna, Bartos Patrycja, Buła Monika, Ulrich Mateusz, Pietrwalski Daniel, Swoboda Jakub, Popielarczyk Adriana, Żak Natalia

\section{Bibliography}

3D Urban Mapping: From Pretty Pictures to 3D GIS An Esri® White Paper December (2014) https://www.esri.com/library/whitepapers/pdfs/3d-urban-mapping.pdf [access 2020.12.31]

4 design days https://www.4dd.pl/2019/pl/makieta-gornoslasko-zaglebiowskiej-metropolii/284/ https://www.4dd.pl/2019/pl/makieta-gornoslasko-zaglebiowskiej-metropolii/284/[access 2020.12.31]

Alcock G.L., Blyt H. (2010), Defining, Profiling and Accommodating Learning Diversity in an International PBL-Environment Horsens (2010), https://upcommons.upc.edu/bitstream/handle/ 2099/10399/ale09p-paper29.pdf

Bradecki T., Cabaj M. (2018), Project-based learning framework for large groups: the case study of the Silesian Metropolis (GZM) model - iceri2018 Proceedings, 11th annual International Conference of Education, Research and Innovation pages: 9853-9862 ISBN: 978-84-09-05948-5 ISSN: 2340-1095 doi: 10.21125/iceri.2018.0823

Cambridge Dictionary https://dictionary.cambridge.org/pl/dictionary/english/mapping [access 2020.12.31]

Cirulis A., Brigmanis K. (2013), 3D Outdoor Augmented Reality for Architecture and Urban Planning, Procedia Computer Science, Volume 25, Pages 71-79, ISSN 1877-0509, https://doi.org/10.1016/j. procs.2013.11.009. (http://www.sciencedirect.com/science/article/pii/S1877050913012143)

Feng Y, Yi Qi. (2018), Modeling Patterns of Land Use in Chinese Cities Using an Integrated Cellular Automata Model. ISPRS International Journal of Geo-Information 7(10), 403; https://doi. org/10.3390/ijgi7100403 
Fonseca D., Redondo E., Sánchez E., Riera A., Valls F. (2017), Educating Urban Designers Using Augmented Reality and Mobile Learning Technologies Móvil RIED. Revista Iberoamericana de Educación a Distancia 20(2), 141-165. DOI: http://dx.doi.org/10.5944/ried.20.2.17675

Gao J., O’Neill B.C. (2020), Mapping global urban land for the 21st century with data-driven simulations and shared socioeconomic pathways. Nature Communications 11, 2302 (2020). https://doi. org/10.1038/s41467-020-15788-7

GZM Metropolis https://metropoliagzm.pl/en/metropolia-dzis/\# [access 2020.01.04] http://www. viewsoftheworld.net [access 2020.12.31] https://vividmaps.com/25-years-urban-growth-densitychange-66-global-cities/ [access 2020.12.31]

Kan T. (2011), QR code based augmented reality applications. In: Handbook of Virtual Reality. Springer, New York, 2011. pp. 339-354.

Lynch K. (1960), The Image of the City. Cambridge, MA: The MIT Press.

McQuilkin A. (2020), The Rise and Fall of Manhattan's Density Animation of changing density across Manhattan | Video by Shlomo Angel and Patrick Lamson-Hall https://urbanomnibus.net/ 2014/10/the-rise-and-fall-of-manhattans-density/ [access 2020.12.31]

Maithani S. (2010), Cellular Automata Based Model of Urban Spatial Growth. Journal of the Indian Society of Remote Sensing 38(4): 604-610. DOI 10.1007/s12524-010-0053-3

Stangel M., Twardoch A. (2016), Students and the City. Real-Live Urban Analysis and Evaluation in Urban Design Education, in: 8. Architektura v perspektive 2016. 8th Architecture in Perspective 2016, red. M. Perinkova, M. Nedved, Ostrava: VSB - Technicka Univerzita Ostrava, 58-56.

Tengyun H., Yang J., Xuecao L, Gong P. (2016), Mapping Urban Land Use by Using Landsat Images and Open Social Data. Remote Sensing 8(2), 151; https://doi.org/10.3390/rs8020151

Valls F., Redondo E., Fonseca D., Torres-Kompen R., Villagrasa S., Nuria Martí N. (2018), Urban Data and Urban Design: A Data Mining Approach to Architecture Education, Telematics and Informatics 35(4), 1039-1052. ISSN 0736-5853, https://doi.org/10.1016/j.tele.2017.09.015

Valls F., Garcia-Almirall P., Redondo E., Fonseca D. (2014), From Raw Data to Meaningful Information: A Representational Approach to Cadastral Databases in Relation to Urban. Planning Future Internet, 6(4), 612-639. DOI: 10.3390/fi6040612

Zlatanova, S., Itard L., Kibria M. S., Van Dorst M. (2010), A User Requirements Study of Digital 3D Models for Urban Renewal. Open House International 35(3), 37-46. 